\title{
La prestación de servicios en el IGV. ENTRE LA NECESIDAD DE DEFINIR EL HECHO GRAVADO Y LA GENERALIDAD DEL IMPUESTO
}

. $+1$ Uar L

\section{Walker Villanueva Gutiérrez}

Abogado por la Pontificia Universidad Católica del Perú. Profesor de la Facultad de Derecho de la Universidad de Lima y de la Pontificia Universidad Católica del Perú. Profesor de la Maestría en Tributación y Política Fiscal de la Universidad de Lima. Master en Asesoría Fiscal por la Universidad de Navarra, España.

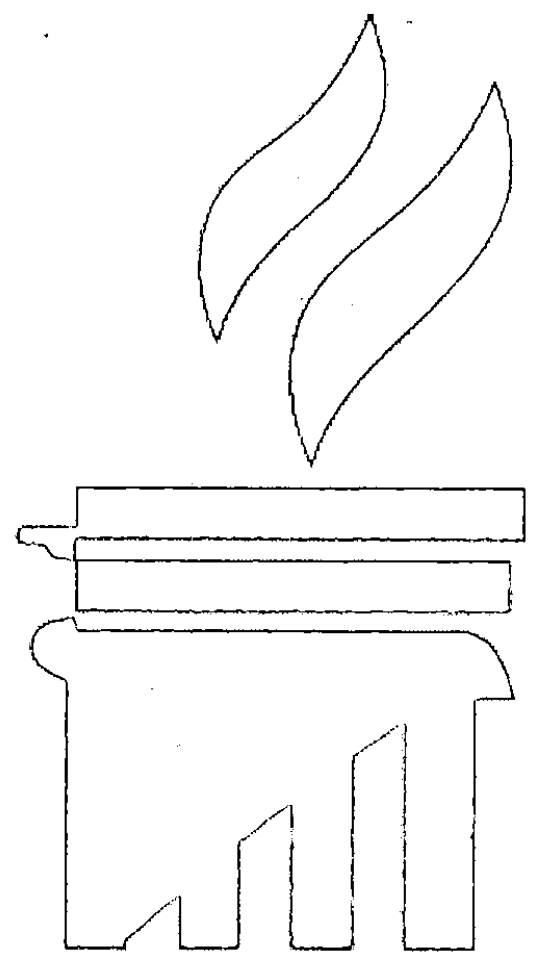

SUMARIO:

I. La definición de las hipótesis de imposición.

II. Definición residual de servicios: .

1. Definición positiva de servicios:

1.1. Definición restrictiva de servicios;

1.2. Definición amplia de servicios:

1.2.1. La definición amplia de servicios en la jurisprudencia del Tribunal Fiscal;

1.3. La definición enunciativa de servicios.

III. Otros requisitos del concepto servicios:

1. La prestación que una persona realiza a favor de otra (la exigencia de alteridad):

1.1. La sucursal establecida en el país como proveedor de servicios a favor de la casa matriz - Jurisprudencia del Tribunal Fiscal;

2. El servicio debe efectuarse a título oneroso:

2.1. El autoconsumo interno de servicios;

2.2. La prestación de servicios a título gratuito: el autoconsumo externo;

2.3. Los servicios gratuitos entre empresas vinculadas;

3. La retribución o ingreso percibido debe considerarse renta de tercera categoria para efectos del Impuesto a la Renta, aun cuando no esté afecto a este impuesto:

3.1. La contraprestación como renta de tercera categoria solo compren de a los supuestos exonerados. 


\section{LA DEFINICIÓN DE LAS HIPÓTESIS DE IMPOSICIÓN}

A nivel de doctrina la definición de los hechos gravados gira en torno a dos supuestos de hecho: (i) la entrega o la venta de bienes y (ii) la prestación de servicios. La diferencia entre uno y otro hecho gravado radica en la distinta oportunidad en que nace la obligación tributaria.

Así, en la prestación de servicios, el Impuesto General a las Ventas debe pagarse en función al criterio de lo percibido, mientras que, en la venta de bienes, no. Esto genera una diferencia sustantiva en cuanto al costo financiero que debe asumir el sujeto del IGV en la venta de bienes respecto de la prestación de servicios.

En nuestra realidad y a nivel de nuestra legislación positiva, la prestación de servicios se ha separado en otro hecho gravado distinto: el contrato de prestación de servicios de construcción. De modo que, en nuestro país, podemos hablar de tres supuestos de hecho diferentes: (i) la venta de bienes muebles o inmuebles, (ii) la prestación de servicios y (iii) los contratos de prestación de servicios de construcción. En este último, la obligación de pago del impuesto se genera con la percepción de la retribución, pero en la prestación de servicio y la venta de bienes muebles no sucede así.

Explicada la razón por la que se conciben distintos supuestos de hecho, si el legislador decidiera que el impuesto se cause uniformemente en todos los hechos gravados en función a lo percibido o en función a otros momentos distintos (v.g. emisión de factura), podría plantearse una definición general y única de la hipótesis de imposición en el impuesto.

Una definición que cumpla con la vocación de generalidad inherente al principio de neutralidad del impuesto, que no genere asimetrías impositivas entre todas las actividades que compiten en el mercado, y que guarde más afinidad con la naturaleza del impuesto como impuesto al consumo y recaudado sobre actividades que generan valor agregado, podría plantearse en la forma que sigue: "toda operación, actividad o prestación que genere la contraprestación debida por ella, cuando tal operación, actividad o prestación genere valor agregado", la cual, naturalmente, podría ser completada con una definición del autoconsumo interno y externo de bienes y servicios.

En este sentido, Cosciani señalaba que el concepto amplio de servicios debería limitarse a aquellos que generan un valor agregado. Este autor sostiene:

"Teniendo en cuenta que el impuesto es al valor agregado y tiende a gravar bienes y servicios de carácter final, aquella definición debe interpretarse en el sentido de que para considerar una operación como prestación de servicios, debe ser de naturaleza tal que determine un valoragregado (transporte, seguro, publicidad, servicios de custodia, etc.) en un proceso de producción de bienes y servicios, con exclusión de cualquier otra operación" (Cosciani 1969: 211).

Esta vocación de generalidad inherente al impuesto se consigue con la definición residual de servicios, como "toda operación que no constituye venta o entrega de bienes". Examinada esta opción para abordar los supuestos de hechos en el impuesto, se llega al mismo "puerto", aunque por caminos diferentes. En realidad, con esta definición se grava cualquier operación, actividad o prestación bajo el concepto de servicios en la medida en que no constituya venta o entrega de bienes.

El concepto de servicios busca concretizar la vocación de generalidad y neutralidad del Impuesto al Valor Agregado. Derouin (1981: 51) señala que "si la noción de entrega de bien puede definirse con una precisión relativa, la de prestación de servicios es en cambio mucho más delicada de definir".' En atención a esta delicada tarea, en la definición de la hipótesis

1 Conviene rescatar lo señalado por Manuel DE JUANO, para quien: 
de imposición "servicios" hemos observado tres distintas opciones en Derecho comparado:

La referida definición residual de los servicios adoptada por la Unión Europea, que define los servicios como toda operación que no constituya entrega de bienes.

La definición positiva de los servicios, que consiste en dar una definición explícita de las operaciones que constituyen servicios.

La definición enunciativa de servicios que pretende abarcar, a través de una relación enunciativa, todas las prestaciones de servicios posibles que comprenda este tipo de operaciones.

\section{DEFINICIÓN RESIDUAL DE SERVICIOS}

Las legislaciones que adoptan esta concepción siguen el criterio de la antigua Sexta Directiva de la Comunidad Económica Europea (actual Unión Europea), en cuyo artículo 6 (actual artículo 24 de la Directiva No. 2006/112/CE del Consejo de la Unión Europea del 28 de noviembre del
2006, relativa al sistema común del impuesto sobré el valor añadido) disponía que 2: "Serán consideradas "prestaciones de servicios" todas las operaciones que no constituyen una entrega de bienes".

Al respecto, se afirma que la definición de prestación de servicios solo tiene un papel accesorio en relación con el hecho imponible venta de bienes, además de ser imprecisa y no constituir una definición técnica. Nuestra opinión, por el contrario, es que el concepto de servicios definido en esta forma viene a ser el hecho imponible principal, porque cualquier operación, actividad o prestación se encuentra gravada con el impuesto sin necesidad de analizar si el contrato, negocio o acto celebrado por las partes ha generado una prestación de hacer, de no hacer o de dar.

Esta definición es también criticada por su vaguedad y ensalzada por su vocación de generalidad y neutralidad. En efecto, se dice respecto de esta definición ${ }^{3}$ :

"[La definición de prestación de servicios] (...) que por su imprecisión ha recibido nu-

"La prestación de servicios no es ni puede equipararse juridicamente por su naturaleza a una venta (...). El servicio, como el trabajo humano, está muy estrechamente ligado a la existencia, a la preservación, a la seguridad y a la dignidad del hombre. Decir que se compran o se venden servicios no se ajusta a la naturaleza de las cosas. El servicio se presta por que el pone su trabajo o su esfuerzo o su sacrificio en favor de otro, a cambio de una retribución, no le da dominio o la pertenencia de su fuente que lo produce que es el mismo hombre en su azarosa existencia" (DE JUANO, Manuel, 1975: 49).

2 Al respecto, SEMINARIO DAPELLO comenta que:

"Muchas legislaciones prefieren no dar una definición sobre la noción de prestación de servicios. Para ello, optan por decir que servicio es todo aquello que no configura entrega de bienes, aunque incida en la cifra de negocios. Es decir, se trata de todos los negocios que no son venta o entrega de bienes. De modo que el concepto de operaciones que inciden en la cifra de negocios involucra tanto la venta o entrega de bienes como los negocios materializados en prestaciones donde no hay ni venta ni entrega de bienes. Lo que significa que como venta de bienes se comprende sobre todo obligaciones de dar, en tanto que como prestaciones de servicios se comprende sobre todo obligaciones de hacer o de no hacer" (SEMINARIO DAPELLO, 2003: 87).

3 PLAZAS VEGA señala:

"(...) la doctrina europea no ha sido unánime en sus planteamientos sobre la definición de la sexta directriz. Para algunos, esa aparente generalidad envuelve una imprecisión que, en definitiva, culmina en la aplicación, en la práctica, de un sistema selectivo de gravamen para los casos contemplados en las normas a modo de ejemplo. Otros, por el contrario, consideran que la generalidad y el tipo residual del hecho generador en comentario permiten un criterio amplio de interpretación para la calificación de operaciones sujetas al IVA, en virtud del cual la consideración de la actividad como servicio es la regla general y su tratamiento como entrega la excepción, aplicable únicamente si se cumplen los precisos parámetros previstos en la directriz comunitaria y en las legislaciones internas para tal fin" (PLAZAS VEGA, 1998: 379). 
merosas críticas, sibien tampoco debe dejarse de reconocer que la falta de precisión es, si no disculpable, si al menos comprensible, por al menos, dos razones: en primer lugar, porque resulta sumamente dificil dar una noción correcta y certera de estas operaciones que abarque el muy amplio abanico de situaciones que el IVA, debido a su vocación de generalidad, pretende gravar; y, en segundo término $y$, sobre todo porque si la Sexta Directiva hubiese definido de modo más preciso y técnico el concepto de prestaciones de servicios, ello hubiese muy probablemente colisionado de manera frontal con el derecho interno de alguno de los estados miembros (Checa González, 2002: 35)".

Rodrigo Ruiz, al comentar la Sexta Directiva, señala:

"Tan imprecisa técnica de configuración de las prestaciones de servicios, que no tiene más virtud que la extraordinaria comodidad que al legislador que confiere ese modo de proceder, aclara y resuelve bien pocas cosas, por lo que es oportuno traer a colación las manifestaciones que sobre el particular realiza Ferreiro - a las que me adhiero plenamente-, cuando al referirse a las Directivas comunitarias, el autor señala que estas tampoco son inmunes a la crítica que por obligación estamos obligados a hacer quienes como universitarios nos dedicamos al análisis de las decisiones del poder que se convierten en norma jurídica. Piénsese, por ejemplo, en la tan fácil como inútil definición negativa de prestación de servicios realizada por la Sexta Directiva. (...) El concepto de servicios, en definitiva, se toma por el legislador al margen por completo del sentido técnicojurídico, e incluso usual, que el término posee, adoptándose a modo de un enorme cajón de sastre donde cabe, en principio, todo aquello que, como se ha dicho, no puede ser calificado como entrega de bienes. La vaguedad que alcanza una delimitación de esta indole es tan grande que no solo resulta absolutamente inútil para poder precisar, desde una perspectiva positiva, cuando nos hallamos ante una prestación de servicios, sino que se revela también insuficiente para acotar, de manera negativa, las operaciones que caen fuera de dicho concepto gravado" (Rodrigo Ruiz, 1987: 217).

No obstante la dura crítica que ha recibido esta definición residual de servicios, la ventaja de esta definición es que cualquier operación que constituya una actividad económica de mercado se encontrará sujeta al IVA y se respetará el principio de generalidad y neutralidad. Por ello, Blanco (2004: 79) concluye que "la definición por vía residual de las prestaciones de servicios constituye en verdad la técnica legislativa más adecuada a los propósitos de generalidad delIVA, vistas las insalvables dificultades que derivarian de una definición por vía enumerativa de las operaciones gravadas (...)".

De lo expuesto, podemos concluir que la razón fundamental de una definición amplia y residual de servicios radica en que "se trata de una solución que permite alcanzar adecuadamente esa vocación de generalidad delIVA (...), evitando todos los inconvenientes de las enumeraciones legales de categorías de negocios" (Blanco, 2004: 25).

La vaguedad de la definición residual de servicios enunciada como toda operación que no constituya entrega de bienes usualmente viene acompañada por una relación enunciativa de servicios específicos. Estos se detallan a fin de apreciar con meridiana exactitud los servicios exonerados.

Sobre el particular, el profesor colombiano Plazas Vega señala que:

"(...) si bien la doctrina acepta este sistema y no el selectivo como el más apropiado para una estructura y técnica del impuesto, y con ese criterio considera un logro positivo cualquier reforma, en tal sentido, no es menos cierto que una medida de esa magnitud envuelve dificultades que deben ser cuidadosamente evaluadas por el legislador para tomar una decisión acertada y, lo que es más importante, acorde con el principio fundamental de justicia. Aún en el sistema de gravamen general, para aludir a una consideración materializada ya en varias legislaciones, se requieren exenciones o exclusiones para los servicios de primera necesidad 
y es también reconocido en materia fiscal que asi como el impuesto, desde el punto de vista de su devengo y causación, tiene un hecho generador, desde el punto de vista negativo, con motivo de exenciones o exclusiones, implica un hecho generador o, en todo caso, una serie de condiciones de tipo fáctico-jurídico cuya ocurrencia da origen al beneficio tributario.

$Y$ naturalmente, el sistema se torna complejo en extremo sila exoneración, comoocurre en la legislación española, conlleva prolijas enumeraciones de servicios exentos que exceden las que regirian en un sistema de especificación de determinadas operaciones gravadas" (Plazas Vega, 1993: 78).

Al ser la definición residual de servicios afín a la vocación de generalidad y neutralidad del impuesto, preocupa que tal definición encierre una indefinición. Así, una descripción tan vaga en el antecedente de la norma tributaria no connotaría las conductas posibles que encajarían en el supuesto de hecho normativo.

Al respecto, el profesor brasileño Paulo de Barros Carvalho señala que:

"(...) el antecedente de la norma jurídica se asienta en el modo ontológico de la posibilidad, lo que quiere decir que los eventos de la realidad tangiblemente recogidos en él tendrán que pertenecer al campo de lo posible. Si la hipótesis efectúa la previsión del hecho imposible, la consecuencia, que prescribe una relación deontológica entre dos o más sujetos, nunca se instalará, no pudiendo la regla tener eficacia social. Estaría comprometida en el lado semántico, volviéndose inoperante para la regulación de conducta intersubjetivas. Se trataría de un sinsentido deontológico, aunque pudiese satisfacer los criterios de organización sintáctica" (Barros Carvalho, 2002: 60).

La definición residual podría no cumplir con el modo ontológico de la posibilidad del antecedente normativo, pues, como señala De Barros Carvalho (2002: 139) "el hecho se caracteriza por tener rigurosamente establecidos, además del núcleo factual, sus coordenadas determinantes de espacio y tiempo". Esta rigurosidad en la descripción de las conductas que constituyen el núcleo fáctico faltaria en la definición residual de servicios. De manera que conduciría a una regla tan vaga que sería inoperante para la regulación de conductas intersubjetivas $y$, por lo tanto, podría cuestionarse por ausencia de definición del hecho gravado.

\section{Definición positiva de servicios}

La definición que hemos denominado positiva de servicios se caracteriza por proponer un núcleo fáctico de las posibles conductas que encajarían en su contenido:

\section{"(...) ese núcleo al que nos referimos está for- mado, invariablemente, por un verbo, seguido de su complemento. De ahi que aludamos al comportamiento humano, tomada la expre- sión en la plenitud de su fuerza significativa, es decir, alcanzando no solo las actividades reflejadas (verbos que expresan acción), sino también las espontáneas (verbos de estado: ser, estar, permanecer, etc.)" (Barros Carvalho, 2007: 220).}

La inclusión de un núcleo fáctico nos parece más adecuada con la estructura de la norma jurídica y con el carácter ontológico del antecedente normativo, que debe describir conductas posibles de la realidad social. Ese núcleo fáctico puede ser abordado usando vocablos en sentido técnico jurídico (prestación de hacer, de no hacer o de dar), o vocablos con significación común (acción, operación, actividad) y se debe tenier siempre presente la vocación de generalidad y neutralidad del impuesto.

En este sentido, el profesor Plazas Vega propone la siguiente definición:

"La prestación de una obligación de hacer o de no hacer, a cargo de una o más personas $y$ a favor de otra y otras, como contrapartida directa y relativamente equivalente al pago de un precio y dentro de un contexto de valor agregado, en la medida en que la actividad de que se trate no se encuentre expresamente excluida por la Ley" (Plazas Vega, 1998: 380).

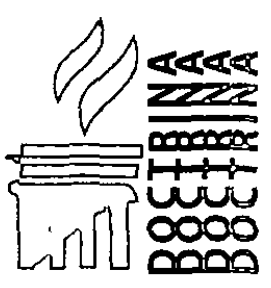


Otra alternativa es la definición de servicios de la legislación chilena, que la establece como:"toda acción o prestación que una persona realiza para otra y por la cual percibe un interés, una prima, comisión o cualquier otra forma de remuneración".

\subsection{Definición restrictiva de servicios}

La definición restrictiva de servicios usualmente incluye a las prestaciones de hacer y de no hacer. Esto, definitivamente, delimita mejor el núcleo fáctico del hecho gravado. Empero, adviértase que tal delimitación precisa no es afín con la vocación de generalidad y neutralidad del impuesto.

Esta circunstancia nos permite apreciar que la tarea de definición de la hipótesis de imposición "servicios" se traslada entre dos coordenadas de signo opuesto (por un lado, la necesidad de precisión del núcleo fáctico gravado y, por otro, la generalidad y neutralidad del impuesto). Dentro de ellas, el legislador deberá buscar con la mejor técnica legislativa un justo medio que concilie la necesidad de una descripción del núcleo fáctico de servicios y la vocación de generalidad y neutralidad del impuesto, sin caer en la vaguedad o imprecisión que se le atribuye a la definición residual de servicios.

En la legislación comparada, por ejemplo, la colombiana, se aprecia una definición restrictiva de servicios que se limita a las prestaciones de hacer y, por excepción, a las de no hacer. Así, siguiendo a Plazas Vega, este nos indica que el Decreto Reglamentario No. 1372 de 1992 de la Ley $6^{\mathrm{a}}$ del mismo año define a los servicios en los siguientes términos:

"Se considera servicio toda actividad, labor o trabajo prestado por una persona natural o juridica, o por una sociedad de hecho, sin relación laboral con quien contrata la ejecución que se concreta en una obligación de hacer, sin importar que en la misma predomine el factor material o intelectual, y que genera una contraprestación en dinero o en especie, independientemente de su denominación o forma de remuneración" (Plazas Vega, 1998: 380).

En nuestra legislación, la definición de servicios que contiene nuestra Ley se interpretó en sentido restrictivo como comprensiva de prestaciones de hacer y de no hacer $y$, excepcionalmente, las de arrendamiento y arrendamiento financiero. ${ }^{3}$

\footnotetext{
"Toda prestación que una persona realiza para otra y por la cual percibe una retribución o ingreso que se considere renta de tercera categoría para los efectos del Impuesto a la Renta, aun cuando no esté afecto a este último impuesto; incluidos el arrendamiento de bienes muebles e inmuebles y el arrendamiento financiero" (el subrayado es nuestro).
}

El sustento de esta interpretación era que la norma se refiere por excepción a dos negocios jurídicos cuya prestación principal es la de dar el bien mueble o inmueble. Por este motivo solo estas prestaciones de dar encajarian en la definición de servicios.

\subsection{Definición amplia de servicios}

La definición amplia de servicios es la que, teóricamente, debería representar una conciliación bastante más acabada entre exigencia de descripción del núcleo fáctico del hecho gravado y la vocación de generalidad y neutralidad del impuesto.

En nuestro pais, la ley anterior a la vigente definía servicios como "toda acción o prestación que una persona realiza para otra y por la cual percibe una retribución o ingreso que se considere renta de tercera categoría". Ello podía ser interpretado con el alcance más amplio posible basado en el vocablo "acción" y también en la referencia no adjetivada de "prestación".

El vocablo acción no tiene connotación jurídica, salvo en el Derecho penal. Sin embargo, esto no

4 Véase al respecto: BRAVO SHEEN y VILLANUEVA GUTIÉRREZ (1998: 202). 
ocurre así en el Derecho privado o de los negocios jurídicos con los que se intercambian bienes y servicios; mientras que el vocablo prestación es el comportamiento del deudor que constituye el objeto del derecho de crédito del acreedor con el cual satisface su interés.

La definición tradicional de prestación "como comportamiento o conducta del deudor consistente en un dar, un hacer o un no hacer, tendiente a satisfacer el interés del acreedor" (De la Puente y Lavalle, 1991: 277) ha devenido en insuficiente para abarcar todas las posibles conductas que puede desplegar el deudor en la ejecución de la prestación. Piénsese en el intercambio de intangibles o derechos incorpóreos o en el comercio electrónico de bienes o servicios.

En este sentido, Giorgianni señala que:

\begin{abstract}
"(...) no cabe duda que la vieja distinción (dare, facere, praestare) no podría agotar, ni siquiera si fuera "modernizada", la lista del contenido de los "comportamientos". Ya se ha reconocido efectivamente la extrema "ductibilidad" del objeto de la relación obligatoria, en el sentido que toda expresión de la actividad humana puede constituir, en abstracto, el contenido de la prestación; y de que solo pueden trazarse -negativamente-los límites impuestos por el ordenamiento (en relación, sobre todo, con la posibilidad y la licitud del comportamiento debido)" (Giorgianni, 2003: 180).
\end{abstract}

En consecuencia, el comportamiento del deudor puede tener un contenido diverso, sin necesidad de encasillar tal comportamiento en una prestación de hacer, no hacer y de dar. Esto haría innecesaria la tradicional distinción de prestaciones (hacer, no hacer, de dar) y bastaría una prestación del deudor como comportamiento dirigido a satisfacer el interés del acreedor, lo cual sería más acorde con la vocación de generalidad y neutralidad del impuesto.

En la doctrina nacional, Leysser León sostiene que:

"(...) en el Código Civil Peruano, aunque es perfectamente posible demostrar que el con- trato tiene efectos reales (Forno Florez, Escobar Rozas), continúan exhibiéndose, yen demasía, normas repetitivas de una tripartición que en la actualidad es a todas luces cuestionable (las obligaciones "de dar", "de hacer", de "no hacer") y acaso inútil" (León, 2007: 26).

Por su parte, Giorgianni señala que:

"(...) no nos ha parecido necesario especificar, como se hace a veces, que el comportamiento del deudor, esto es, el contenido de llamada prestación, pueda consistir en dar, en hacer o en no hacer: en efecto, aun admitido que esta triple distinción agote todos los posibles supuestos de la prestación del deudor, no nos parece que el contenido de la prestación del deudor pueda concurrir a individuar la obligación. Es necesario considerar que todo comportamiento, siempre que sea patrimonialmente valorable y pueda satisfacer el interés (aunque no sea patrimonial) de otro sujeto, puede constituir el contenido de la prestación del deudor; mientras que se puede decir igualmente que todo comportamiento puede constituir el contenido del deber jurídico en general, y no solo la obligación" (Giorgianni, 1958: 136):

Si se asume que la entrega o venta de bienes, en cualquiera de sus dos vertientes doctrinarias, comprende la transferencia de propiedad civil (tendencia jurídica) o la transmisión del poder de disposición sobre los bienes (tendencia económica), la prestación de servicios comprendería toda prestación en sentido jurídico que no se superponga con la prestación derivada de la venta o de la entrega de bienes.

Sin embargo, la definición de servicios en torno al concepto de prestación en sentido técnico jurídico abarcaría solo aquellas situaciones jurídicas en que el comportamiento del deudor satisfaga el interés del acreedor. Pero no comprendería las situaciones jurídicas en que el titular del poder jurídico satisfaga su interés sin mediar un comportamiento del deudor (derecho reales) o aquellas situaciones jurídicas de sujeción (derecho reales de garantía).

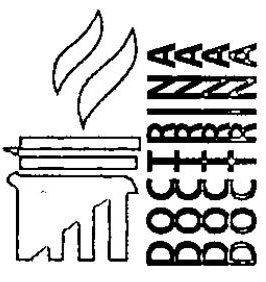

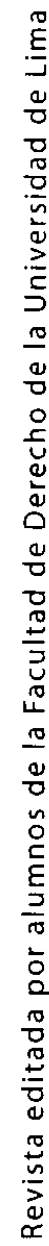

$\frac{9}{2}$
$\frac{2}{8}$
$\frac{8}{8}$
$\frac{8}{8}$ 
Desde este punto de vista, el contenido de prestación sería todo comportamiento destinado a crear una relación jurídica de contenido patrimonial. Esta puede consistir en una relación jurídica obligatoria, una relación jurídica real, una relación jurídica de sujeción o cualquier otra situación jurídica.

Así, el contenido de prestación comprendería los derechos de crédito, los derechos reales de goce o de disfrute y los derechos reales de garantía u otras situaciones jurídicas distintas (de sujeción, de carga). De manera que lo relevante es que exista una prestación como comportamiento dirigido a generar una relación jurídica patrimonial. Ello, en definitiva, incluiría toda la gama de prestaciones como contenido de la obligación y también las conductas destinadas a la constitución de derechos reales de goce o de garantía u otras situaciones jurídicas.

Ya Giorgianni advertía que existen ciertas relaciones obligatorias en que el interés del acreedor se satisface mediante un poder inmediato sobre la cosa, y no por la cooperación de la conducta del deudor; en otros casos, el derecho real se satisface mediante una relación obligatoria.

"Debe decirse que el interés (de goce) del titular es realizado mediante un poder inmediato sobre la cosa no solo en la enfiteusis, en el usufructo, en el uso, en la habitación y en la servidumbre positiva, sino también, por las razones antes expuestas, en el arrendamiento, en el comodato y en la anticresis; mientras, por el contrario, en la servidumbre negativa, como antes hemos intentando demostrar, el interés del titular debe entenderse realizado mediante una relación obligatoria" (Giorgianni, 1958: 95).

\subsubsection{La definición amplia de servicios en la jurisprudencia del Tribunal Fiscal}

En la Ley del Impuesto General a las Ventas se define la hipótesis de imposición referida a los servicios en el artículo 3, literal c), numeral 1, en los términos siguientes:

"Toda prestación que una persona realiza para otra y por la cual percibe una retribución o in- greso que se considere renta de tercera categoría para los efectos del Impuesto a la Renta, aun cuando no esté afecto a este último impuesto; incluidos el arrendamiento de bienes muebles e inmuebles y el arrendamiento financiero".

Debemos notar que la Ley del IGV no alude solo a la prestación como conducta destinada a satisfacer el interés del acreedor, en cuyo caso únicamente estarian previstas como hipótesis de imposición las relaciones jurídicas obligatorias, mas no así las relaciones jurídicas reales o cualquier otra situación jurídica creada por la autonomía privada de las partes en uso de su libertad contractual.

Conforme hemos explicado en líneas anteriores, la prestación sería cualquier conducta que constituya el contenido de una relación jurídica obligatoria, excluida la prestación destinada a transferir la propiedad de los bienes, o la conducta destinada a la generación de una relación jurídica patrimonial distinta a la obligación.

Y nótese que decimos contenido de una relación jurídica obligatoria o relación jurídica patrimonial, por cuanto la ley exige una contraprestación (retribución o ingreso) a consecuencia de dicha prestación. En este orden de ideas, la constitución del derecho de superficie, de la servidumbre, del usufructo, a título oneroso, entre otras situaciones jurídicas, encajaría en el concepto de servicios y como tal se encontrarían gravados con el impuesto.

En definitiva, al igual que en el Derecho civil, la tradicional distinción en prestaciones de hacer, de no hacer o de dar "temporales" como contenido del concepto de servicios en el impuesto, ha devenido obsoleta y no responde siquiera con meridiano alcance el diverso contenido que puede asumir la prestación como conducta destinada a satisfacer el interés del acreedor. Menos aún, abarcaría otro tipo de relaciones jurídicas en las que la conducta del deudor no es el medio para satisfacer el interés de la otra parte o el titular del derecho o situación jurídica.

\section{a) La prestación comprende obligaciones de dar, hacer y no hacer}


El Tribunal Fiscal, en las Resoluciones No. 51305-2002, de fecha 4 de setiembre del 2002, y No. 8296-1-2004, de fecha 26 de octubre del 2004, señala que el concepto de servicios abarca las obligaciones de dar, hacer y no hacer, de esta manera:

"(...) la definición de servicios contenida en la Ley del Impuesto General a las Ventas [...] es bastante amplia, pues el término prestación comprende tanto las obligaciones de dar, salvo aquellas en las que se dan en propiedad el bien, en cuyo caso estariamos ante una venta, como las de hacer y no hacer".

Del mismo modo, el Tribunal Fiscal, en las Resoluciones No. 2028-4-1996, de fecha 9 de agosto de 1996, y No. 1008-5-1997, de fecha 14 de julio de 1997, declara que:

"(...) las prestaciones de dar que implican la transferencia de bienes muebles en propiedad están comprendidas en las operaciones de - venta; en tanto que la definición de servicios comprende las prestaciones de hacer y, excepcionalmente, cuando el servicio es definido como arrendamiento de bienes muebles $e$ inmuebles, a las prestaciones de dar que importan cesión de bienes en uso".

\section{b) La prestación de servicios comprende la cesión temporal de bienes intangibles}

Respecto a los bienes intangibles, el Tribunal Fiscal, en la Resolución No. 225-5-2000, de fecha 28 de marzo del 2000 , sostiene que:

"(...) la cesión de uso de una marca origina el pago de regalias, figura que califica como arrendamiento o cesión temporalen uso de un bien intangible, operación que, como se ha desarrollado en los párrafos anteriores, se encuentra gravada con el Impuesto General a las Ventas".
En general, cabe recordar que la cesión temporal de los bienes intangibles considerados bienes muebles (marcas, patentes, derechos de autor, derechos de llave) a través de contratos de licencia calificaría como prestación de servicios. Por su lado, la cesión definitiva a través de contratos de cesión calificaría como una venta de bienes muebles en el país. ${ }^{5}$

Otro caso de prestación de dar temporal es el de los contratos de cesión minera. Sobre este punto, el Tribunal Fiscal, en la Resolución No. 5130-5-2002, de fecha 4 de septiembre del 2002, declara que:

"Las concesiones mineras pueden ser objeto de diversos contratos, como son el contrato de transferencia, contrato de opción minera y el contrato de cesión minera. En el caso específico del contrato de cesión minera, el concesionario entrega su concesión minera a un tercero, percibiendo una compensación (...). Como resultado de la celebración del contrato, el cesionario sustituye temporalmente en todos los derechos y obligaciones al cedente en la concesión a cambio de la mencionada compensación. (...) lo que principalmente se otorga es el uso o goce del conjunto de derechos que conforman la concesión y que conllevan la explotación económica para hacer suyos los productos. [Como puede apreciarse, el contrato de cesión minera consiste en prestaciones de dar] en uso un conjunto de derechos que conforman la concesión, las que además se hacen a título oneroso, siendo los ingresos que percibe la recurrente (cedente), al ser una persona jurídica, renta de tercera categoría para efectos del Impuesto a la Renta, por lo que la operación realizada califica como una prestación de servicios".

Sin embargo, es importante precisar que el criterio contenido en la Resolución del Tribu-

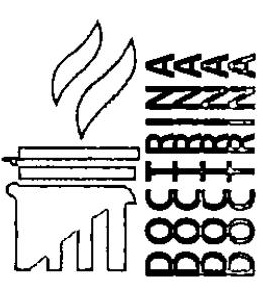


nal Fiscal No. 05905-1-2004, de fecha 17 de julio del 2004, donde este ha establecido que la cesión definitiva de la concesión minera no se encuentra gravada con el impuesto, porque no constituye bien mueble para fines del impuesto:

\section{"(...) la concesión minera no comparte ninguna} característica de los intangibles mencionados, sino que por el contrario es considerada por la legislación civily minera como un bien inmueble, por lo que su transferencia no constituye una operación gravada, según lo establecido en el literal a) del artículo 1 de la Ley del Impuesto general a las Ventas".

\section{c) La cesión de uso permanente de sepulturas no encaja en el concepto de servicios}

El Tribunal Fiscal, en la Resolución No. 66703-2002, de fecha 19 de noviembre de 2002, al analizar el caso de la cesión en uso permanente de sepulturas, declara que:

"(...) atendiendo a que la recurrente únicamente es concesionaria de la explotación y mantenimiento del cementerio, la concesión del derecho de uso permanente de sepultura otorgado, a su vez, por la recurrente constituye, en estricto, la cesión de un derecho, y por tanto, un acto juridico cuyo objeto es un bien intangible o incorporal; cabe advertirse, además, que siendo este un derecho referente a un bien inmueble, no encuadra en la definición de bien mueble en el inciso b) del articulo 3 de las Leyes citadas anteriormente. (...) consecuentemente, tales operaciones no se encontraban gravadas con el impuesto General a las Ventas en los periodos materia de análisis".

Nótese que el Tribunal Fiscal descarta la existencia de un hecho gravado porque la cesión en uso de la sepultura es un derecho incorporal que no constituye bien mueble $y$, como tal, no encajaría en el concepto de servicios. Sin embargo, la definición amplia de servicios, en el sentido que hemos propuesto, abarcaría incluso las cesiones permanentes de intangibles en la medida en que no transfieran la propiedad, incluso cuando dichos intangibles no califiquen como bienes muebles.

Debe recordarse, que la cesión temporal de bienes intangibles o incorporales se encontraba gravada bajo el concepto de servicios. Asimismo, la cesión definitiva de tales bienes no estaba gravada, porque nuestra anterior Ley no incluía a tales bienes dentro del concepto de bienes muebles.

En consecuencia, la cesión permanente de sepulturas calificaría dentro del concepto de servicios por tratarse de una conducta (prestación) por la cual se percibe una contraprestación.

\subsection{La definición enunciativa de servicios}

Ciertamente, la enunciación de supuestos específicos de los servicios gravados permite ilustrar y dar un mensaje normativo de pedagogía. Sin embargo, la definición de servicios con una lista enunciativa de servicios sin proporcionar una definición general sería insuficiente e inútil, por la ductibilidad de las conductas que pueden encajar dentro del concepto de prestación. Como señala Plazas Vega (1993:77), esta concepción de los hechos generadores especificos puede generar en que la misma norma da lugar a interpretaciones encontradas y, en ocasiones, a prácticas de evasión. O, en todo caso, a determinaciones económicas afectadas por el aspecto tributario con desmedro del llamado principio de neutralidad. Ello, a pesar de la conocida regla según la cual, en materia tributaria, las formas jurídicas no deben dar origen a verdades diferentes de las realidades económicas.

\section{OTROS REQUISITOS DEL CONCEPTO SERVICIOS}

Entre los requisitos para la configuración de la prestación de servicios, nuestra norma señala que esta debe cumplir los siguientes requisitos. Es decir, debe ser: "toda prestación que una persona realiza para otra (exigencia de alteridad) y por la cual se percibe una retribución (contra- 
prestación) que se considere renta de tercera categoría".

\section{La prestación que una persona realiza a favor de otra (la exigencia de alteridad)}

La prestación que una persona realice a favor de otra es la exigencia de bilateralidad o alteridad en la relación jurídica patrimonial. De manera que la ejecución de servicios para sí mismo no está gravada con el impuesto.

Como señala Blanco (2004: 110), “(...) los supuestos en los que se asienta la formulación jurídica del hecho gravado del IVA hacen forzoso limitar a este, en principio; a las operaciones con pluralidad de partes". Es decir, el hecho de gravar los consumos, tanto en la venta de bienes como en las prestaciones de servicios, forzadamente genera la bilateralidad de partes, por cuanto de no existir esta no se podría gravar el consumo, con el valor agregado generado ya que ella presupone la participación de por lo menos dos sujetos en las operaciones sujetas al impuesto.

\subsection{La Sucursal establecida en el pais como proveedor de servicios a favor de la Casa Matriz - Jurisprudencia del Tribunal Fiscal}

En la Resolución del Tribunal Fiscal No: 1651-5-2004 de fecha 19 de marzo del 2004, el Tribunal Fiscal señala que los servicios prestados por la Sucursal a favor de la casa matriz se encuentran gravados con el IGV, bajo los fundamentos siguientes:

“(...) para determinar cuándo un sujeto es domiciliado para efectos del Impuesto General a la Ventas, las normas que regulan dicho tributo remiten a la legislación prevista en el Impuesto a la Renta.

Que de las normas citadas se infiere que las disposiciones que regulan el impuesto consideran a la sucursal de una empresa establecida en el exterior como un sujeto distinto a su matriz, pues mientras la primera es considerada como un sujeto domiciliado que puede prestar servicios en el país gravados con el impuesto, la matriz conserva su naturaleza de no domiciliada y los servicios que presta y sean consumidos o empleados en el territorio nacional estarán gravados bajo un supuesto distinto: utilización de servicios.

Que ello es concordante con la autonomía administrativa y contable de la que gozan las sucursales del exterior constituidas en el Perú en las operaciones que realizan, las que deben inscribirse en el Registro Único de Contribuyentes (RUC) y emitir comprobantes de pago con su razón social, entre otras obligaciones formales tributarias.

Que no puede sostenerse que para efecto del IGV, la sucursal de una empresa establecida en el exterior constituye un solo sujeto con su casa matriz, pues ello implicaría que la primera solo podría considerarse como un sujeto no domiciliado (calidad de su matriz) contrariamente a las normas que regulan dicho impuesto.

Que sibien es cierto que desde el punto de vista del derecho comercial, la sucursal carece de personeríajurídica independiente de sumatriz, ello no impide que para efectos tributarios,

6 En la Resolución de Tribunal Fiscal No. 05130-5-2002, se grafica cómo se aplican estos requisitos:

"(...) según la ley, se exigen los siguientes requisitos:

a) Que se trate de una acción o prestación realizada por una persona para otra.

b) Que la persona que efectúe la acción o prestación perciba una retribución o ingreso.

c) Que el ingreso sea considerado como renta de tercera categoría, aun cuando no esté afecto al Impuesto a la Renta.

En el caso del contrato de cesión minera en análisis, como se ha explicado lineas arriba, existen prestaciones que el cedente realiza a favor del cesionario, como el dar en uso un conjunto de derechos que conforman la conseción, las que además se hacen a título oneroso, siendo los ingresos que percibe la recurrente (cedente), al ser una persona jurídica, renta de tercera categoría para efectos del impuesto a la Renta, por lo que la operación realizada califica como una prestación de servicios". 
tratándose de sucursales de sujetos no domiciliados, se les considere como sujetos independientes. Respecto a ello, Antonio Lovisolo, al tratar sobre los establecimientos permanentes como centros de imputación subjetiva, señala que" (...) a los fines fiscales, la casa matriz y su establecimiento permanente son considerados como autónomos y diversos centros de referencia de imputación de obligaciones jurídicas, a semejanza de lo que se verificaría entre dos sujetos autónomos aunque vinculados entre si por un interés económico común".

Que por otro lado el artículo 396 de la Ley General de Sociedades, aprobada por la Ley 26887, establece que "Es sucursal todo establecimiento secundario a través del cual una sociedad desarrolla, en lugar distinto a su domicilio, determinadas actividades comprendidas dentro de su objeto social. La sucursal carece de personeria juridica independiente de su principal. Está dotada de representación legal permanente y goza de autonomía en gestión en el ámbito de las actividades que la principalle asigna, conforme a los poderes que otorga a sus representantes".

Que con respecto a ello, Enrique Elías Laroza, al comentar sobre las sucursales de personas juridicas constituidas en el extranjero, señala que "(...) sibien la definición de sucursal contenida en el artículo 396 de la LGS resulta aplicable a todas las sucursales establecidas en el pais, con independencia del lugar de constitución de la principal, existen diferencias prácticas entre ambos tipos de sucursales que justifican un tratamiento diferenciado en ciertas materias sin que ello comprometa la unicidad del concepto de sucursal en la legislación peruana. (...) Por estas razones, existe como una constante en la legislación peruana, un tratamiento diferenciado entre ambos tipos de sucursales, que tiende a asimilar a las sucursales de sociedades constituidas en el extranjero a sociedades con personalidad propia (...).

Que de acuerdo a lo señalado se concluye que la sucursal es un sujeto independiente de su matriz para efecto del Impuesto General a las Ventas".
No compartimos los fundamentos del Tribunal Fiscal por las razones que pasamos a explicar:

(i) Si bien la Ley del IGV se remite a las normas del Impuesto a la Renta para la determinación del domicilio, debemos hacer notar que esta condición solo es aplicable a aquellas entidades que sean sujetos del impuesto. Según el artículo 9 de nuestra Ley, las sucursales de empresas constituidas en el extranjero no tienen la condición de sujetos; se reconoce la condición de sujeto a la persona jurídica, mas no asi a la sucursal. La persona jurídica constituida en el extranjero para fines de determinar su domicilio se considera persona domiciliada en el país, empero no apreciamos ninguna norma que le otorgue la calidad de sujeto del IGV a la sucursal como un ente distinto de la matriz.

(ii) La definición de persona jurídica regulada en la Ley del Impuesto a la Renta, en que se reconoce expresamente a la sucursal como persona jurídica distinta a la matriz, no es trasladable al ámbito del IGV, porque entendemos que la aplicación supletoria solo es posible cuando la finalidad de los impuestos no se distorsiona.

\section{El servicio debe efectuarse a título oneroso}

La definición de servicios alude a "toda prestación (...) por la cual [se] percibe una retribución o ingreso que se considere renta de tercera categoría para los efectos del Impuesto a la Renta". Así, los servicios solo constituyen hipótesis de imposición cuando sean ejecutados a título oneroso $y$, concretamente, cuando se ejecute en correspondencia a una contraprestación.

Esta referencia a la onerosidad como contraprestación se realiza con un doble propósito. La exclusión de los servicios a título gratuito de la hipótesis de imposición y la exclusión de los servicios "dependientes" e "independientes" a través de la exigencia de que la contraprestación constituya renta de tercera categoría. 
La referencia a la contraprestación dentro de la definición material de la hipótesis de imposición de servicios debe interpretarse en forma concordada con la base imponible del impuesto. Esta se define como "la suma total que queda obligado a pagar el adquirente".

En consecuencia, las prestaciones de servicios, en general, tendrán carácter oneroso cuando de por medio exista una retribución o ingreso que sea considerada renta de tercera categoría.

En otros ordenamientos jurídicos, como sostiene López (2001: 59), "la mediación o existencia de contraprestación al tiempo de realizarse (...) las prestaciones de servicios (...) es uno de los requisitos configuradores del hecho imponible del IVA". Así, a fin de calificar a la operación como onerosa para efectos del impuesto, la contraprestación debe efectuarse a cambio de la prestación de un servicio.

Por ello, Blanco (2004:91) afirma que "(...) para que exista onerosidad a los efectos del hecho generador del IVA, basta que exista una contraprestación. [Además de] (...) que dicha contraprestación es algo que se recibe por parte de quien entrega o presta el servicio".

En este sentido se pronuncia el Tribunal Fiscal con resolución No. 1651-5-2004, de fecha 19 de marzo del 2004, cuando señala que:

"(...) los contratos onerosos son aquellos en los cuales cada una de las partes sufre un sacrificio que se compensa con una ventaja. Que de acuerdo a la definición de la Enciclopedia Jurídica Omeba, sobre el contrato a título oneroso "casi siempre la onerosidad va unida a la bilateralidad del contrato no porque se trate de conceptos idénticos, sino solo en razón de que, existiendo prestaciones recíprocas en el momento del perfeccionamiento contractual, esas prestaciones se han tenido en cuenta como uno de los fines del contrato".

Quela onerosidad de un contrato no se encuentra vinculada a la ganancia (renta o utilidad) que obtenga una de las partes, como sostiene la Administración, sino a las prestaciones y contraprestaciones de cada una de las partes, (...) cabe indicar que de acuerdo con la ley del IGV, la retribución por el servicio prestado se encuentra gravada con el impuesto aun cuando parte o el total de ella se destinen a cubrir el costo del servicio que se realice en tanto que no se acredite que el "reembolso de gasto" se haya efectuado por cuenta del usuario y que los comprobantes de pago figuren a nombre de este último".

En este mismo sentido, Ramírez Gómez sigue la jurisprudencia del Tribunal de Justicia de de la Comunidad Europea y señala que:

"(...) para que una operación resulte "imponible" es preciso que esta se efectúe a título oneroso, lo que implica la existencia de "un contravalor, de una prestación a cambio de una entrega de bienes o prestación de servicios, en otras palabras, es preciso la existencia de una transacción entre las partes y que se haya pactado un precio o contravalor" (Ramírez Gomez 1997: 55).

Además, este autor también sostiene que dicho "contravalor debe cumplir ciertas exigencias o requisitos para que pueda hablarse de la existencia de una contraprestación; por ende, de una operación afecta al impuesto". Estas son las siguientes ${ }^{8}$ :

1. Entre el servicio prestado y la contraprestación recibida debe existir una relación

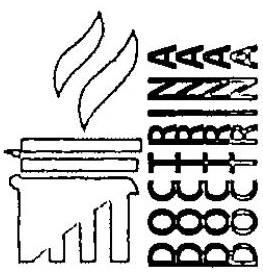

7 En la Resolución del Tribunal Fiscal No. 4517-1-2002, de fecha 9 de agosto de 2002, se señala que: "(...) el servicio de alimentación que presta la recurrente a sus trabajadores en sus propios comedores tiene la condición de servicio afecto al Impuesto General a las Ventas, resultando irrelevante el tratamiento que la ley laboral otorgue a los referidos ingresos".

8 Véase: RAMÍREZ GOMEZ (1997: 55-56). 
directa, un vínculo directo, es decir, debe existir un intercambio contractual.

2. El contravalor debe poder expresarse en términos monetarios.

3. El contravalor debe tener un valor subjetivo, ya que la base imponible es la contraprestación realmente percibida y no un valor estimado mediante criterios objetivos.

En el mismo sentido, en referencia a la legislación uruguaya, Blanco sostiene que la contraprestación debe tener una vinculación directa con la entrega del bien y la prestación del servicio. Por ello, comenta:

“(...) lo esencial para entender que se está en presencia de una operación onerosa es que el sujeto que (...) presta el servicio recibe una contraprestación que se asocia precisamente $a(. .$.$) ese servicio, por lo cual la recepción de$ otras compensaciones no asociadas directamente a las mismas no es suficiente para calificar como onerosa (...) la prestación de un servicio en concreto" (Blanco 2004: 92).

\subsection{El autoconsumo interno de servicios}

El autoconsumo interno consiste en los servicios realizados por la propia empresa para sí misma. Estos no se encuentran gravados con el impuesto por no cumplir con la bilateralidad de las partes y porque no implica la ejecución de una contraprestación.

La inafectación del autoconsumo de servicios se sustenta en el hecho de que, contrariamente a los bienes muebles, los servicios no poseen un soporte material que haga susceptible el control y fiscalización por parte de la Administración de los consumos. Es en esta dificultad en la que se fundamenta el hecho de que la mayoría de las legislaciones excluyen este supuesto del campo de aplicación del impuesto, a diferencia de los autoconsumos de bienes, como en el caso de nuestro país donde el retiro de bienes si se asimila a la venta de bienes. ${ }^{9}$

Este hecho se presenta pese que el sujeto del impuesto pueda deducir el crédito fiscal de los bienes y servicios que a su vez le permiten realizar este autoconsumo. En este caso, se pondera el gravamen del servicio autoconsumido con el costo que genera su control, y resulta, como ya se explicó, más factible su inafectación que su gravamen.

\subsection{La prestación de servicios a título gratuito: el autoconsumo externo}

La prestación de servicios a título gratuito, si bien no está gravada con el impuesto, sí genera un costo impositivo. La realización de este tipo de operación da lugar a aplicar la regla de la prorrata de crédito fiscal y, con ello, parte del crédito fiscal no se recupera como tal y se debe utilizar como costo o gasto para fines del Impuesto a la Renta. La única excepción a dicha regla se da si el servicio gratuito se presta a título de bonificación sobre ventas realizadas por el contribuyente. En ese caso, el servicio ejecutado en ese contexto no origina prorrata de crédito fiscal.

El contribuyente está obligado a emitir los correspondientes comprobantes de pago, de acuerdo al Reglamento de Comprobantes de Pago, en los que consignará la frase "servicio prestado gratuitamente". Adicionalmente, se señalará el valor del servicio prestado que hubiera correspondido a dicha operación.

Existe, sin embargo, un supuesto gravado de autoconsumo externo: "La entrega a título gratuito que no implique transferencia de propiedad de bienes que conforman el activo fijo de una empresa vinculada a otra económicamente, salvo en los casos señalados en el Reglamento". Estamos frente una prestación de servicios a título gratuito respecto de bienes del activo 
fijo cuando cedente y cesionario sean empresas vinculadas.

En este caso, existe una omisión en la relación jurídica de repercusión del cedente al cesionario. No existe una norma que prohíba el traslado del impuesto, de modo que se aplicaría la regla general del artículo 38 de la Ley, conforme a la cual el usuario está obligado a aceptar el traslado del impuesto.

Si este fuera el caso, el cesionario debería poder utilizar el impuesto repercutido en la prestación de servicios gratuitos como crédito fiscal, aun cuando la cesión gratuita de bienes no genere ningún costo o gasto para fines del Impuesto a la Renta. Por el contrario, si el impuesto fuera asumido por el cedente, este no podría deducir ese importe como costo o gasto para fines del Impuesto a la Renta: en principio, conforme al artículo 38 de Ley, el importe del mismo debería ser asumido por el usuario del bien.

\subsection{Los servicios gratuitos entre empresas vinculadas}

Según el artículo 32 de la Ley del Impuesto a la Renta, todas las transacciones entre empresas, vinculadas o no, deben realizarse a valor de mercado. Más aún, la norma, en su penúltimo párrafo, establece que:"lo dispuesto en el presente artículo será también de aplicación para efectos del IGV". Cabe entonces preguntarse: ¿deben gravarse los servicios gratuitos con el IGV?

Consideramos que la regla contenida en el artículo 32 de la Ley del Impuesto a la Renta se aplica en el ámbito del IGV con sujeción a las reglas contenidas en la Ley del IGV. Esto es, observando las normas de la base imponible del IGV, las normas del crédito fiscal en el IGV, y las normas de nacimiento de la obligación tributaria, las cuales tienen como premisa la contraprestación real pactada en una transacción económica.

De este modo, si según la Ley del IGV los servicios gratuitos no están gravados con el IGV, no lo estarán por aplicación del artículo 32 de la
Ley del Impuesto a la Renta. De la misma forma, si según la Ley del IGV la base imponible es la contraprestación, esta no puede quedar desvirtuada por la regla de valor de mercado contenida en el artículo 32 de la Ley del Impuesto a la Renta: se alteraría el funcionamiento mismo del IGV, que está basado en débitos fiscales y créditos fiscales reales $y$ no en débito fiscales $y$ créditos fiscales "imputados" o "presuntos".

\section{La retribución o ingreso percibido debe considerase renta de tercera categoría para efectos del Impuesto a la Renta, aun cuando no esté afecto a este impuesto.}

La definición de servicios recogida por la Ley del IGV señala que es: "toda prestación que una persona realiza para otra y por la cual percibe una retribución o ingreso que se considere renta de tercera categoría para los efectos del Impuesto a la Renta, aun cuando no esté afecto a este último impuesto; incluidos el arrendamiento de bienes muebles e inmuebles y el arrendamiento financiero".

Que el hecho que la norma señale: "(...) por la cual percibe una retribución o ingreso que se considere renta de tercera categoría para los efectos dellmpuesto a la Renta, aun cuando no esté afecto a este último impuesto", debe entenderse que este ingreso tiene que calificar objetivamente como una renta de tercera categoría conforme a las teorías de renta (renta producto, renta flujo de riqueza o la teoría de renta incremento de flujo patrimonial más consumo en los supuestos que fuera aplicable). Por tanto no interesa si subjetivamente el sujeto esté gravado, exonerado o inclusive inafecto del impuesto a la renta.

Tal criterio se desprende de las Resoluciones No. 6828-4-2002, de fecha 22 de noviembre del 2002; No. 557-4-2001, de fecha 4 de mayo del 2001; No. 537-4-2001, de fecha 30 de abril del 2001; No. 303-4-2000, de fecha 31 de marzo del 2000; No. 799-4-1997, de fecha 20 de agosto de 1997 y No. 2400-4-1996, de fecha 12 de noviembre de 1996. Así, precisamente en la primera Resolución citada se sostiene:

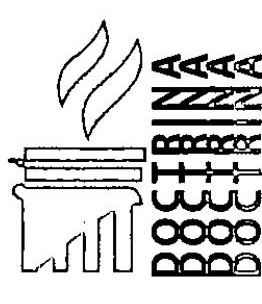


"Que mediante las Resoluciones No. 537-42001 y 557-4-2001, este Tribunal señaló que la recurrente se encontraba afecta al IGV por los servicios médico asistenciales y hospitalarios onerosos brindados (...), indicando que cuando el artículo 3 de los textos de la Ley del IGV aprobados por Decretos Legislativos 775 y 821 , hacen referencia a los ingresos que constituyen rentas de tercera categoría para efectos del impuesto a la renta, se refiere a la categorización de los diversos ingresos y no a que se requiere pagar el impuesto a la Renta para que exista la afectación con el IGV. (...) asimismo, este Tribunal precisó que si bien la recurrente en su calidad de entidad de auxilio mutuo, se encontraba inafecta allmpuesto a la Renta, en virtud del inciso d) del artículo 18 de la Ley del Impuesto a la Renta aprobado por el Decreto Legislativo 774 , las rentas que obtenía calificaban como rentas de tercera categoría, conforme a los dispuesto en el artículo 28 de la misma Ley, y los servicios que generaban tales rentas los prestaban de manera habitual, por lo que los mismos se encontraban gravados con el IGV" (el subrayado es nuestro).

Igualmente, la Resolución No. 799-4-1997, de fecha 20 de agosto de 1997, señala que:

"(...) se debe precisar que cuando la Ley del IGV precintada hace alusión a que los servicios prestados deben constituir renta de tercera categoria para efectos del Impuesto a la Renta, no está señalando que para la persona que presta el servicio debe ser un ingreso gravado de tercera categoría, sino tan solo que dicho impuesto debe tener tal naturaleza y por tanto estar incluidas en el articulo 28 del Decreto ley, aun cuando el Instituto Nacional de Administración Pública se encuentre exonerado en forma subjetiva del Impuesto a la Renta" (el subrayado es nuestro).

\subsection{La contraprestación como renta de tercera categoría solo comprende a los supuestos exonerados.}

La Ley del IGV, con respecto a la retribución por los servicios, señala que: "(...) se considere renta de tercera categoria para los efectos del Impuesto a la Renta, aún cuando no esté afecto a este último impuesto (...)", esta debía interpretarse de la siguiente forma.

Nótese que, de una lectura concordada de ambas normas, la retribución debe ser renta de tercera categoría, aun cuando no esté afecto al Impuesto a la Renta. Conforme a esta interpretación concordada, las prestaciones de servicios para estar gravadas con el IGV debian encontrarse dentro del ámbito de aplicación del Impuesto a la Renta, lo que abarcaría solo a los sujetos exonerados del IGV, mas no así a los inafectos, porque solo así la renta podría calificarse como de tercera categoría. ${ }^{10}$

Si se tratara de sujetos exonerados, la retribución que ellos generan sí podría calificarse como renta de tercera categoría. En cambio, si los sujetos estuvieran inafectos del Impuesto a la Renta, la renta generada por ello no puede clasificarse como de tercera categoría.

Así, en la Resolución del Tribunal Fiscal No. 9331-1994 se señalaba que:

"(...) cabe referir que las entidades como la recurrente no están exoneradas del IGV, sino que no estan sujetas, tanto al Impuesto a la Renta como al impuesto a las ventas; (...)

10 BASSALLO señala al respecto que:

"Actualmente se encuentra aclarada la duda que presentaba el texto original, al incluir expresamente que se encontrara gravado con el IGV el ingreso que se considere renta de tercera categoria para efectos del impuesto a la Renta, aun cuando no esté afecto a este último impuesto. Con el texto original no quedaba claro si se encontraban gravados los ingresos calificados como de tercera categoría por la Ley dell mpuesto a la Renta generados por un sujeto inafecto o exonerado de dicho impuesto. Tal es asi, que el Tribunal Fiscal en un primer momento adoptó la posición según la cual no se consideraban afectos al $/ \mathrm{GV}$ los servicios prestados por sujetos inafectos al Impuesto a la Renta, aunque constituyeran en estricto renta de tercera categoria" (BASALLO RAMOS, 2008: 38). 
las no sujeciones implican que las entidades que no generan renta, desde el punto de vista impositivo, no se encuentran incluidas en la hipótesis de incidencia, por lo que su exclusión del marco conceptual de los tributos referidos, opera de suyo, no siendo necesario que se expliciten en el texto legal, que el hecho que el legislador haga una descripción de las no sujeciones o no incidencias no significa que deban estar escritas, porque fluyen de la propia concepción del tributo".

Por otro lado, con respecto a la frase en comentario, debemos resaltar que es la única hipótesis de imposición en que la Ley exige que la contraprestación sea renta de tercera categoría. Ello obedece -entendemos- al propósito de excluir del hecho gravado a los servicios que generen rentas de primera, segunda, cuarta y quinta categorías.

En este sentido, consideramos que hubiera sido más adecuado excluir mediante una inafectación legal a todos los servicios que califiquen como rentas de primera, segunda, cuarta y quinta categoría. Esto no generaría mayor duda y se evitarían mayores problemas de interpretación para la tributación del impuesto por aquellos sujetos inafectos de él que realicen habitualmente actividades gravadas con el impuesto. Este es el caso de los entes públicos y entidades de auxilio mutuo, en tanto que las prestaciones de servicios no empresariales no generan renta de 3 categoría, toda vez que estas se encuentran inafectas al Impuesto a la Renta (artículo 18, inciso a y b).

De este modo, el Tribunal Fiscal ha interpretado que cuando la norma refiere "aun cuando no esté afecto al impuesto a la Renta", esta comprende tanto a los sujetos inafectos como a los exonerados, y basta que la contraprestación califique objetivamente como renta gravada de tercera categoría conforme a las teorías de renta aplicable a las personas jurídicas.

En definitiva, consideramos que la exigencia normativa de que la contraprestación sea calificada como renta de tercera categoría es una redundancia con la norma contenida en el artículo 9, inciso 1 de la Ley del IGV: La razón es que, al tratarse de actividades empresariales o de actividades habituales, la contraprestación que se perciba por tales actividades objetivamente sería una renta de tercera categoría.

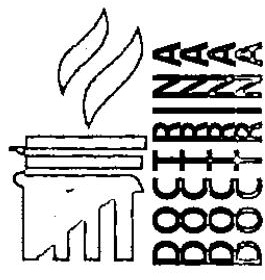

